\title{
La extensión universitaria desde un enfoque bio-eco-ético-social. Diálogo entre lo local y lo científico
}

Pérez, Francisco; Albujar, Joselin; Rodríguez, Diamary

La extensión universitaria desde un enfoque bio-eco-ético-social. Diálogo entre lo local y lo científico

Revista Educación, vol. 43, núm. 1, 2019

Universidad de Costa Rica, Costa Rica

Disponible en: http://www.redalyc.org/articulo.oa?id=44057415019

DOI: https://doi.org/10.15517/revedu.v43i1.27928

Esta obra está bajo una Licencia Creative Commons Atribución-NoComercial-SinDerivar 3.0 Internacional. 


\section{La extensión universitaria desde un enfoque bio-eco-ético-social. Diálogo entre lo} local y lo científico

University extension programs from a bio-eco-social-approach. A dialogue between local and scientific knowledge

Francisco Pérez

Universidad de Carabobo, Venezuela

javierpr1987@gmail.com

(iD http://orcid.org/0000-0002-5460-1210

\section{Joselin Albujar}

Universidad de Carabobo, Venezuela

joselinalbujar@hotmail.com

(iD http://orcid.org/0000-0002-5460-1210

Diamary Rodriguez

Universidad de Carabobo, Venezuela

diamarysr@gmail.com

iD http://orcid.org/0000-0002-6406-1502
DOI: https://doi.org/10.15517/revedu.v43i1.27928

Redalyc: http://www.redalyc.org/articulo.oa?id=44057415019
Recepción: 17 Febrero 2017

Aprobación: 09 Noviembre 2018

\section{Resumen:}

La extensión comprende la responsabilidad y la función social de la academia universitaria. Pero, en la actualidad su concepción ha evolucionado, se han incorporado elementos que acentúan su trascendencia en la formación ciudadana de los universitarios. A la luz de lo precedente este trabajo de investigación tuvo como propósito reflexionar respecto a la extensión universitaria en la contemporaneidad, considerando su naturaleza dialógica y compleja. La metodología se sustentó en un ejercicio hermenéutico apoyado en una rigurosa revisión del estado del arte. De tal proceso se generaron aportes y recomendaciones en busca de alimentar el debate en cuanto a la extensión que apuntan a sustentar a la extensión universitaria desde una visión compleja, basada en la incorporación de las dimensiones Bio-Eco-Ético-Social, a fin de responder a la naturaleza reticular e interconectada de la realidad, asumiendo al ser humano como una persona sumida en un contexto complejo y cambiante, entendiendo a la extensión desde una naturaleza dialógica, de interacción entre lo científico y lo popular.

Palabras ClaVe: Extensión universitaria, Educación, Ciencia, Saberes locales.

\section{Abstract:}

Academic extension courses represent an important social and Academia. Today, however, this concept has evolved to include Citizenship Education among university students. The objective of this study is to reflect on current university extension programs, analyze its theoretical foundation and how it serves as a dialogue incorporating both local grassroots and scientific knowledge from a more complex perspective. A rigorous literature review was done, for this purpose which makes contributions and theoretical recommendations regarding contemporary extension programs. It also looks at the need for sustainable university extension programs that include a more complex Bio-Eco-Ethical-Social dimension which reflects the evolving nature of human beings. Extension programs should, therefore, be capable of reflecting the dialogical and comprehensive nature of both a scientific and grassroots approach.

KEYWORDS: University extension programs, Scientific education, Grassroots knowledge.

\section{NotAS DE AUTOR}

javierpr1987@gmail.com 


\section{A MANera DE INTRODUCCión}

En la contemporaneidad, la universidad se caracteriza por cumplir tres grandes funciones, como son la docencia, la investigación y la extensión, las cuales no han sido desarrolladas bajo la misma importancia y rigor. Esto se puede entender desde la historia de la Universidad tradicional, aquella que tiene sus anales en la Universidad de Berlín en 1810, donde se inicia la conjunción entre la docencia y la investigación científica, sustentando el aprendizaje de conocimientos basados en metateorías y donde los académicos solo tenían como propósito formar a una pequeña élite de las sociedades (Morales, Mira y Arias, 2010).

Más recientemente, en 1918 surge el concepto de extensión, de la mano del denominado Movimiento o la Reforma de Córdoba, una corriente cargada de ideas revolucionarias del seno de la clase media, en búsqueda de accesos a la vida universitaria, como medida de presión a la oligarquía y el clero; es a partir de allí que se reconoce a la extensión como aquella con la misión de vincular a la universidad con la sociedad, volcándose sobre ella a fin de formar conciencia cívica (Tünnermann, 2000; Ortiz y Morales, 2011).

La extensión universitaria como "la tercera función sustantiva de las universidades y como el elemento dinamizador que facilita el flujo continuo de conocimientos compartidos entre los académicos, innovadores, cultores y la sociedad en general" (Tünnermann, 2000. p. 269). Naturalmente que tales cambios en la historicidad universitaria permitieron fortalecer la función social de universidad como institución. No obstante, esa denominación como tercera función sustantiva lastimosamente dejó en desventaja a la extensión frente a la docencia y la investigación.

Empero, en la actualidad, la concepción de extensión ha evolucionado, se han incorporado planteamientos diversos los cuales han nutrido su rol dentro de la dinámica universitaria. A continuación, asomamos algunas posturas que resultan pertinentes pues evidencian lo comentado respecto a la evolución de la concepción de la extensión universitaria.

La extensión se concibe como misión y función orientadora de la universidad, esto lo asevera Sánchez (2010) quien esgrime:

\footnotetext{
...esta es entendida como ejercicio de la vocación universitaria. Por su contenido y procedimiento, la Extensión Universitaria se funda en el conjunto de estudios y actividades filosóficas, científicas, artísticas, culturales y técnicas, mediante el cual se auscultan, exploran y recogen del medio social, nacional y universal, los problemas, datos y valores culturales que existen en todos los grupos sociales (p. 12).
}

Al considerar este planteamiento se entiende que la extensión echa mano de la producción intelectual y técnica de la universidad para ponerla al servicio de la comunidad, asumiendo ese escenario como una fuente importante de rasgos sociales y culturales de los cuales la universidad se debe nutrir. Pues no solo con producir intelectualmente y preservar el sustrato cultural y moral, la universidad cumple con el encargo social, necesita promocionar lo que hace a fin de generar el mayor impacto positivo en la colectividad en pro del desarrollo y progreso (Pérez, Silva, Sainz y Caridad, 2014).

Por otra parte, Torales y Barrios en 2017 enuncian que la extensión universitaria es aquel proceso en el cual se forja una conciencia de solidaridad, aquella que se constituye "donde los universitarios y los diferentes actores sociales colaboran en la construcción de situaciones de mayor justicia y equidad para lograr el desarrollo, tanto individual como colectivo" (p. 101). De estas ideas se puede aseverar que se derrumba la postura en la cual se argumenta un nexo unidireccional, donde solo hay una contribución de la universidad hacia la sociedad y no en sentido contrario, de hecho se supera la idea que pone por encima a la universidad como fuente de conocimiento e intelectualidad sobre las comunidades como reserva de saberes populares. De esta última idea, se visualiza con claridad que la universidad moderna está consciente de su indivisible relación con las sociedades y de su papel fundamental como garantes de desarrollo y progreso.

Entendiéndola así, no solo como un espacio donde la universidad se reivindica frente a la sociedad, sino también como una vía de primera mano para la generación de conocimientos y saberes contextualizados, 
amerita que tenga cimientos claros que sustenten la praxis, pues la realidad abordada dista mucho de la determinada, objetivada y segmentada verdad que se estudia e inculca en las aulas de la universidad tradicional. Es necesario tomar una postura que conciba al ser humano desde su totalidad, por ejemplo al asumir una perspectiva holística puede poseer múltiples dimensiones, pues el ser humano es de naturaleza compleja, un ser que debe concebirse en una esfera planetaria, en una trama biológica y perteneciente en una red social y axiológica (Schmidt, 2011). Esta idea da la posibilidad de repensar la extensión universitaria en cuanto a la forma de concebir el contexto y a su vez las respuestas que dará a las demandas de la sociedad.

De tales ideas y cuestionamientos surgió la imperiosa necesidad de repensar la extensión, no solo desde un modismo o una tendencia epistémica, sino de la ineludible realidad que tiene la universidad ante sí; una realidad cambiante, caótica, compleja, reticular, diversa; una realidad que no solo necesita formar profesionales y hacer investigación científica o social, sino que demanda hilvanar la docencia y la investigación con la actividad extensionista, apostando a la tenencia de una postura epistémica divergente a las tradicionales y modernas, que garantice una acción universitaria la cual le otorgue la misma importancia a la docencia, a la investigación y a la extensión.

La idea primigenia es pensar en una extensión que vaya más allá del cumplimiento de un servicio a la comunidad por parte de estudiantes y profesores, o de la oferta de cursos, talleres de formación permanente; sino que sea un espacio para la producción intelectual útil, para la vinculación comunitaria en el marco de un diálogo entre los saberes locales y populares junto al conocimiento científico, un diálogo de entendimiento y reflexión; un diálogo que no debe ser azaroso y tampoco determinado, pero que demanda ser sustentado y repensado desde los logos filosóficos y epistemológicos, esta última idea es el referente de mayor importancia en esta disertación.

Ahora bien, hasta ahora han emergido planteamientos los cuales han enriquecido el debate sobre la extensión universitaria, por ejemplo, el indivisible nexo entre la universidad y la comunidad, la implicación que tiene la extensión en el desarrollo y progreso colectivo e individual y la resonancia que esta tiene en la exploración de la equidad y la justicia, son ideas que resulta imperativo no perderlas de vista, pues están dictando tendencia en cuanto al papel de la extensión tanto dentro de la universidad como fuera de ella.

De hecho, abordar estos elementos en un contexto como el nuestro, donde el venezolano derivado de una crisis compleja y multidimensional tiene un contexto tan adverso, acentúa la demanda de una universidad que dé respuesta, ideas, luces para salir de este atolladero. En estos tiempos la universidad venezolana no debe retroceder, debe replegarse en su contexto, debe atender a la sociedad vapuleada y para ello debe acentuar la actividad extensionista.

Todo lo anterior llevó a esgrimir un planteamiento el cual adosará aspectos epistemológicos, ontológicos y axiológicos que permitiesen el diálogo entre los saberes locales y el conocimiento científico, entre la universidad con su academia y la comunidad con sus saberes populares, todo ello en el marco de una perspectiva compleja, cónsona con la realidad social y cultural de los pueblos.

Vale acotar que tal ejercicio de naturaleza hermenéutica e interpretativa nos llevó a generar aportes para ser referentes conceptuales en la actividad extensionista, hecho que se demuestra a través de los gráficos y estructuras que buscan representar las ideas emergentes.

\section{ANÁLISIS Y DISERTACIÓN}

\section{La universidad y la extensión en pleno siglo XXI}

El rezago de la universidad como institución formativa de las sociedades ante un escenario global, dinámico, fluido e interconectado, hoy por hoy resulta más evidente, pues al parecer los cambios no ocurren de la educación a la sociedad, sino que la educación siempre intenta ir tras los cambios acelerados y virtuosos 
que hoy se suscitan en el mundo. En realidades como la nuestra donde elementos sociales, económicos, políticos, culturales y axiológicos acomplejan el escenario, la necesidad de una universidad que dé luces se hace imperativo; de tal forma, que la educación superior no solo debe proporcionar competencias cognitivas y procedimentales sólidas para el mundo de hoy y del mañana, sino que se demanda una formación de egresados con una carga axiológica, con principios éticos para la paz, los derechos humanos y la democracia (Martí y Martí, 2013).

Tal idea, es cónsona con un planteamiento de Petz en el 2015, quien indica que la formación universitaria en la actualidad "no pasa únicamente por la formación de profesionales más comprometidos, sino que involucra también una mirada sobre el lugar de la universidad en la sociedad, además de accionares posibles en los territorios de pertinencia" (p. 1). Véase que sin duda, la universidad hoy día tiene un papel trascendental en la ecuación que dé resultados a los problemas sensibles de la sociedad, por ende al hablar de temas como desarrollo, progreso, derechos humanos, paz y democracia, demanda de la contribución de la universidad, para ello es vital considerar un planteamiento de Machado y García (2014) quienes indican que la universidad y la comunidad forman parte de un mismo sistema, donde los sujetos que hacen vida en él participan y colaboran en pro de las mejoras necesarias, todo esto en el marco de lo que estos mismos autores llaman intercambio dialéctico.

No obstante, para que se cumpla con esa demanda, esta debe considerar estratégica a la extensión, pues es la función que aproxima, comunica, y proyecta a la universidad como institución con su contexto, aunado a que es en el marco de la extensión donde se puede dar una formación integral vinculada con la realidad y con la intención de mejorarla (Arocena, 2011).

Cuando se revisa lo publicado respecto a extensión universitaria en la actualidad y se asoman ideas que apuntan al papel de la extensión en pro del desarrollo, del progreso, de los derechos humanos y la paz en la sociedad queda en evidencia que la universidad da señales de reconocer tal demanda. Cuando se considera que la universidad y la extensión deben apuntar al desarrollo, a fin de expandir las libertades de los individuos como parte de una sociedad, siendo esto no un mero incremento de bienes y capitales, sino la posibilidad de vivir la vida que desean vivir, transformando su contexto e interacción es posible ver el importante papel de la universidad en la generación de desarrollo y progreso (Sen, citado por Vásquez y Castillo, 2013).

Este planteamiento resalta la estratégica labor de la extensión, función vital para que la universidad contribuya para "la innovación, el emprendimiento y el compromiso social en pro de las sociedades" (Naval, García, Puig y Santos, 2011, p. 79). Sin embargo, nosotros cuestionamos, ¿cómo llegar al desarrollo de las sociedades desde la extensión?, ¿cómo promover la innovación y el emprendimiento?, ¿cómo contribuir en la forja de valores?, estos son cuestionamientos por abordarse; no obstante, de primera mano entendemos que demandamos de ciencia, de la producción intelectual útil, contextualizada y significativa para la sociedad, así como de una interacción dialógica entre lo científico y popular que se enmarque en una visión que no segmente la realidad.

\section{Misión y función social}

Más allá de investigar y formar a las sociedades desde la academia en pro del desarrollo y del progreso, la universidad en estos tiempos tiene un rol de impacto social vital. Es desde la extensión que la universidad es un auténtico cuerpo académico de transformación y construcción de la sociedad. Tal aseveración se corrobora cuando se entiende que la universidad tiene una influencia poderosa en los caminos a surcar por una nación en lo económico, social, cultural y político (Martínez, Mavárez, Rojas y Carvallo, 2008). Esta idea en nuestro contexto venezolano, es de suma valía pues ante un escenario tan adverso, la universidad tiene un gran compromiso, no solo de preservar la cultura y la academia venezolana, sino también la indeclinable responsabilidad de dar luces a un pueblo que tanto lo demanda. 
De lo anterior, es válido comentar que los cambios deseados por una nación, con el fin del mejoramiento de su calidad de vida y promover su crecimiento como sociedad, están íntimamente vinculados con la educación, pues la formación de los ciudadanos promoverá los cambios en el modus vivendi de la sociedad con el contexto, carácter que se hace aún más vigente en la contemporaneidad cuando, lo que Tünnermann (1999) expresa como "la brecha de la desigualdad, se hace aún mayor entre las reducidas sociedades poderosas y las grandes masas carentes de desarrollo" ( $\mathrm{p}$ 102), suscitándose problemas que atañen al ser humano, demandando soluciones holísticas y globales; para ello la universidad desde su praxis en la docencia, la investigación y la extensión debe dar herramientas a la sociedad para la reducción de esta brecha de desigualdad, tomando un papel trascendental la extensión.

Ahora bien, ¿por qué la extensión debe ser punta de lanza de la función social de la universidad?, porque más allá de la naturaleza primigenia de la extensión es imperativo considerar ideas emergentes, ideas que indaguen dejar a un lado la etiqueta de función social que la ha señalado como apéndice o añadidura dentro de la dinámica universitaria, para llegar a ser una razón fundamental de la universidad, así lo desarrollado en la actividad académica e investigativa será útil para la sociedad y que mediante esa interacción los universitarios tengan formación ciudadana (García, 2008; Tommasino, 2016).

De tal forma que la actividad extensionista desde sus diversas modalidades, tiene la ineludible misión de ser la función y misión social de la universidad, convirtiéndose en una importante ventana para el diálogo entre la universidad como instancia académica y las comunidades y sus organizaciones, por ende llámese puente, interacción, acción comunicativa, encuentro dialógico, compartir de saberes, o cualquier determinación que se le pueda adjudicar a la extensión universitaria es estratégica para la mejoría de la calidad de vida, para la promoción de los derechos humanos (Vaccarezza, 2015; Torales y Barrios, 2017).

\section{Dimensiones Bio-Eco-Ético-Social}

La ciencia tradicional, la moderna, la cimentada en la Revolución Científica encabezada por ideas de Bacon, Descartes y Newton, se caracteriza por concebir al contexto de estudio como aquel que puede ser reducido, atomizado y segmentado en pequeños recodos para ser abordado de manera objetiva por áreas híper especializadas (Capra, 1992, 1996).

Tal visión, para múltiples autores, se ha traducido en una piedra en el zapato en la actualidad, porque los problemas que hoy atañen a la humanidad son imposibles de ser segmentados y fragmentados en parcelas, debido a su naturaleza compleja, reticular, diversa y difícil de ser reducida (León, 2009).

Aunque estos planteamientos hoy por hoy no son novedosos en las universidades con rasgos tradicionales, ya que las críticas a la ciencia moderna llevan tiempo en el tapete, la praxis de docentes e investigadores no se ha deslastrado de los cánones modernos, evidenciándose no solo en la praxis docente, sino lambien la investigación y la actividad extensionista.

Al respecto Morín (1994) afirma que existe "una falta de adecuación grave y profunda entre los saberes disociados, parcelados, compartimentados en disciplinas con las realidades o problemas cada vez más pluridisciplinarios, transversales, multidimensionales, transnacionales y planetarios" (p.13). Esta atomización es una fiel prueba de que la ciencia clásica ha generado en la mente humana una tendencia natural a buscar regularidades y explicaciones ordenadas, o bien a generar una conducta natural de ordenar las cosas, por medio de semejanzas o diferencias; visión la cual sin duda alguna es incompatible con la naturaleza compleja y reticular que poseen los problemas que afectan a las sociedades en las diversas esferas de la vida planetaria. De tal forma, el pensamiento analítico y racional se ha convertido en un obstáculo para el estudio global de los problemas sistémicos, interconectados e interdependientes y que a su vez se expresan en sus diferentes caras, propias de la misma crisis (Capra 1992, 1996).

Ahora bien, podríamos preguntarnos: ¿Qué relación guarda esto con la extensión?, la relación es la misma que la investigación científica y la docencia han buscado de estar en consonancia con tales corrientes 
emergentes, la extensión universitaria no debe quedarse atrás, no como modismo o tendencia, sino que ciertamente los problemas y las realidades abordadas desde la extensión por medio de proyectos de servicio a la comunidad o de vinculación comunitaria son complejos, reticulares y colmados de múltiples elementos difíciles de separar o segmentar; aunado que además de aportar posibles soluciones a los problemas de las comunidades y contribuir a la formación de las sociedades, en la extensión se generan conocimientos y saberes desde la puesta en práctica de metodologías como la investigación acción y el aprendizaje servicio.

Por tanto, la adopción de una postura integradora, reticular y compleja de la realidad y la consolidación del contexto como un espacio académico idóneo para la pluralidad de los conocimientos y saberes, pasa por asimilar al contexto como una trama donde está indivisible lo social, cultural, biológico, planetario, global, ético y axiológico.

Evidentemente, estas ideas precedentes llevan a tener una comprensión ontológica del ser, de su cuerpo, su espíritu, de su unidad, de su auto pertenencia y alteridad; teniendo cabida lo social, lo ético, lo biológico y lo planetario, por ende, desde esta visión el ser humano posee una moral expresada en sus acciones, tanto a sus semejantes como a su contexto ambiental, recreando espacios de oportunidad y reflexión desde diversas aristas y disciplinas, en especial las vinculadas a lo social (Schmidt, 2011).

Bajo esta idea, resulta pertinente abordar los espacios sociales y comunitarios desde un enfoque el cual discrepe de la visión tradicional moderna. Nosotros, en este ejercicio interpretativo, apostamos a un enfoque complejo, comprendido por el mayor número de dimensiones posibles; en el marco de este ejercicio interpretativo nuestro aporte llega a considerar al contexto desde la dimensión Biológica, la Ecológica, la Ética y la Social.

En este momento del hilo interpretativo vale la pena hacer un inciso y cuestionarse, ¿por qué las dimensiones Bio- Eco - Ético - Social? pues bien, para dar respuesta a este cuestionamiento consideramos la naturaleza holística del ser humano, uno vinculado ineludiblemente con su unión con su contexto, con sus pares y el planeta, un sujeto que hace ver sus rasgos axiológicos, su cultura, sus valores y tradiciones, es por ello que osamos plantear estas cuatro dimensiones fundamentales en este momento de este proceso interpretativo, a razón de lo difícil que resulta comprender a la humanidad desde una sola dimensión obviando su naturaleza holística; claro está sería un error negarse a incorporar más dimensiones, sin embargo en este ejercicio interpretativo asomaremos solo estas.

La dimensión Bio, responde a la mera necesidad de comprender a la vida como aquella donde el ser humano no prima sobre las otras especies. A la búsqueda de discrepar del antropocentrismo heredado de la modernidad, con la dimensión Bio se busca entender la vida como una trama donde los componentes animados e inanimados forman una red rica de detalles e interconexiones, red en la cual la humanidad es identificada como una pequeña rama del árbol de la vida y no como la cúspide de este (Capra, 1992, 1996; Leff, 1998; Sauve, 2004).

Vale acotar que al considerar la insostenible relación ser humano-naturaleza en cuanto al uso exacerbado de recursos naturales y la escueta sensibilidad expresada en una crisis ambiental profunda, es que consideramos prima una respuesta por parte de la universidad, especialmente desde la extensión.

Respecto a la dimensión Eco surge de ideas irreverentes de Morín cuando en 1999 reclamó: "la humanidad debe entender y reconocer que existe dentro de cada ser una identidad terrenal, muy física y muy biológica" (p. 40). Esta aseveración resulta ser muy fáctica, pues se refiere a ese nexo ineludible que radica en lo biológico, no obstante, resultan debatibles las ideas que calan en lo espiritual. Sin embargo, incorporar una dimensión Eco en el marco de la extensión universitaria, permite reconocer al contexto como parte de un todo, es decir, la extensión puede abordar una localidad, pero lo gestado allí resuena en lo global, naturalmente que ello demanda tener una postura con una carga axiológica y valorativa respecto a lo contextual, buscando superar esa postura utilitaria del ser humano a su contexto.

Ahora bien, lo Ético y lo Social resultan difíciles de desmarcar uno del otro, ya que al pensar en dimensiones de esta naturaleza, es imperativo reconocer al ser humano como un ser meramente ontológico, pues mientras 
interactúa con sus pares y su contexto por medio de relaciones sociales, refleja su sistema de valores, su cultura y cánones axiológicos (Schmidt, 2011). Esta idea de Schmidt resulta vital para incorporar a la dimensión ética y la social en el debate debido a que es el marco de esa interacción social y contextual que cobra sentido la extensión.

De las ideas expuestas, surge la necesidad de adentrarnos en la complejidad, pues es un constructo que compone lo epistemológico y ontológico o contextual, prueba de ello es lo descrito por Morín (2000) quien asevera: "lo complejo se refiere a que está tejido junto" (p. 14). Asumir un paradigma o postura compleja, es reconocer que una cosa o aspecto siempre está unida a otra. Donde se encuentran inseparables los constituyentes de un todo. Por ende, adoptar un enfoque el cual contemple dimensiones Bio, Eco, Ético y Social implica reconocer a la complejidad como piso epistemológico y también ontológico en la práctica de los proyectos socio educativo y extensionista en general.

Entonces, concibiendo a la extensión universitaria desde un enfoque que comprenda estas cuatro dimensiones, resultará contraproducente asumirla de manera estática. Al contrario, es vital asumirla como dinámica, abierta e interactiva, siendo así como podría ser fértil una extensión para la generación de conciencia solidaria desde la comunicación e interacción entre la universidad y la sociedad (Del Huerto, 2012; Petz, 2015; Torales y Barrios, 2017). Vale acotar que esta concepción dinámica de la actividad extensionista ha quedado en evidencia a lo largo de las ideas precedentes. Es así como la extensión podría ser un espacio idóneo para el diálogo, para el encuentro, el desencuentro y reconocimiento entre la académica y lo popular, pues no puede existir integración entre la comunidad y la universidad, si dicha relación no se concibe como dinámica y cambiante.

En este punto es necesario cuestionarse: ¿Cómo debe ser tal diálogo?, ¿qué componentes debe contener?, ¿hacia dónde debe dirigirse?, ¿qué propósitos ha de tener? A fin de dar respuesta a estas interrogantes resulta imperativo asomar algunos planteamientos que se inclinan hacia estas ideas; para Torales y Barrios en el 2017 "la extensión universitaria debe ser concebida como un puente entre los conocimientos que brinda la universidad y la sociedad pues la comunicación entre los universitarios y la sociedad ayuda al desarrollo de la conciencia de solidaridad" (p. 102); así mismo Del Huerto en el 2007 comentó que la extensión debe ser una vía de "comunicación cultural" (p. 2).

Estas ideas apuntan a una concepción dinámica y cambiante de la extensión, donde la comunidad y la universidad comparten conocimientos y saberes, encontrándose lo científico con lo popular, pues ambos son importantes en el marco de las problemáticas que aquejan el modus vivendi de las comunidades, en el cual se conglomeran aspectos sociales, culturales, políticos, económicos, entre otros (ver Figura 1). 


\section{Figura 1. Dimensiones Bio-Eco-Ético-Social. Componentes de una visión compleja de la extensión universitaria, como marco del diálogo entre la ciencia y lo popular.}

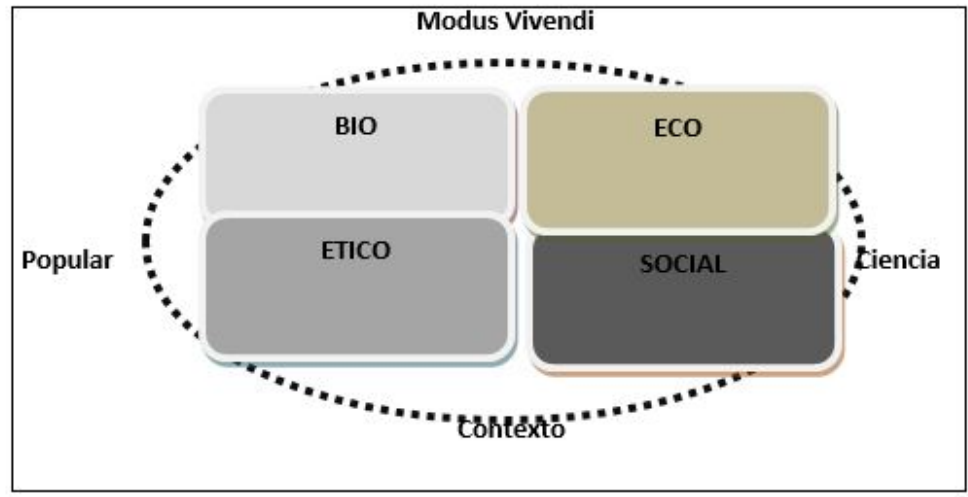

Fuente: Elaboración propia

Figura 1. Dimensiones Bio-Eco-Ético-Social. Componentes de una visión compleja de la extensión universitaria, como marco del diálogo entre la ciencia y lo popular Fuente: Elaboración propia

En este diagrama se muestra que las dimensiones planteadas como son: Bio-Eco-Ético-Social se encuentran adosadas a los componentes del diálogo, los cuales son el modus vivendi, el contexto, los saberes populares y la ciencia, reflejándose que tal diálogo no tiene dirección preestablecida entre la universidad y la comunidad, sino que hay reconocimiento del modus vivendi de las comunidades y su contexto, por ende las imposiciones no tienen asidero. Aseverándose entonces que, desde la extensión universitaria, se debe hablar de un proceso dialógico de otredad, de respeto, valoración y reconocimiento al pensar del otro; es decir, un diálogo holístico y multidimensional, donde tiene cabida la comprensión del ser y de los problemas de las sociedad desde una óptica compleja y multidimensional.

\section{Una extensión dialógica, recursiva e interpretativa}

Hasta ahora este ejercicio interpretativo nos llevó a entender que la extensión universitaria vista desde un enfoque Bio-Eco-Ético-Social tendría una naturaleza compleja, fungiendo como un diálogo entre otros, o bien, un diálogo de otredad, de entendimiento, de reconocimiento y valoración; un espacio entre quienes no son pares, donde el encuentro y el desencuentro tienen asidero desde la dialógica, la recursividad y la interpretación, entendiéndose que tal diálogo entre lo científico y popular es virtuoso y recursivo, pues no tiene direccionalidad y sentido establecido, es dinámico, abierto y rico de detalles, haciéndose entonces casi imposible la fragmentación de los conocimientos y saberes y la segregación de estos con la realidad contextual.

De tal forma que, este diálogo virtuoso y dinámico e integrado solamente tiene validez si las dimensiones Bio-Eco-Ético-Social vienen adosadas de una integración real de conocimientos y saberes y desde una conjugación con el contexto, puesto que contextualización del conocimiento es un paso importante para la eficacia en el funcionamiento cognitivo y también para la aplicación de este en las sociedades. Es por ello, la que en el marco de este ejercicio se plantea que el alcance de la complejidad pasa por un diálogo que promueva la integración de disciplina y la contextualización (ver Figura 2). 


\begin{abstract}
Figura 2. Enfoque Bio-Eco-Ético -Social en la extensión universitaria para el encuentro entre los saberes populares y las ciencias naturales. El diálogo de otredad es factible en las diversas modalidades de la extensión universitaria.
\end{abstract}

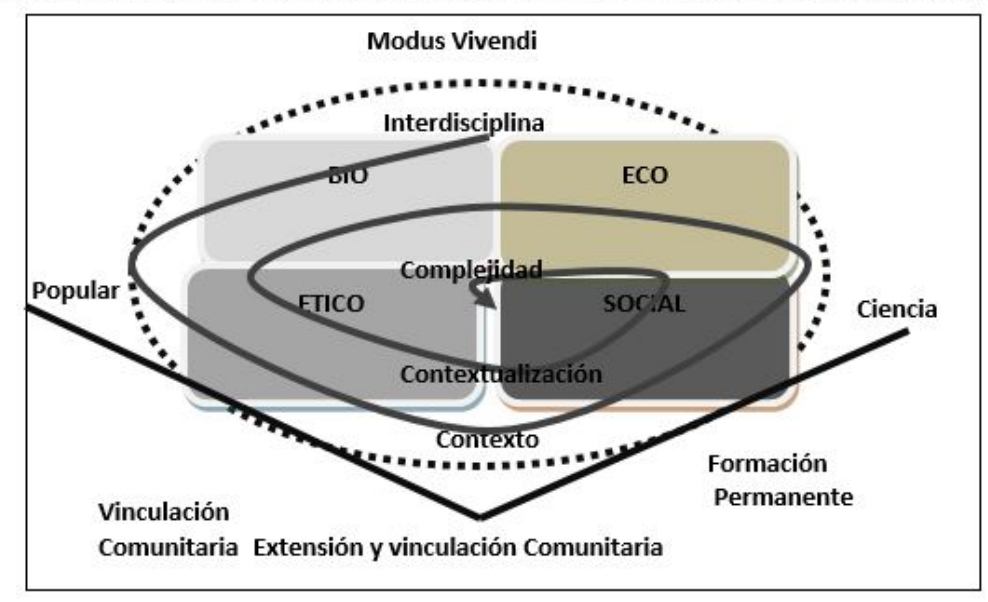

Fuente: Elaboración propia

Figura 2. Enfoque Bio-Eco-Ético -Social en la extensión universitaria para el encuentro entre los saberes populares y las ciencias naturales. El diálogo de otredad es factible en las diversas modalidades de la extensión universitaria Fuente: Elaboración propia

Resulta importante acotar que este dinamismo y recursividad el cual nutre a la extensión universitaria es reforzado por lo descrito por Ortiz y Morales (2011) quienes exponen que las políticas de extensión no pueden ser estáticas; por tanto las acciones que se implementen deben estar vinculadas a las necesidades del entorno, necesidades que cambian, no se agotan y se retroalimentan y fluctúan, y a medida que pasa el tiempo se incorporan elementos, prueba de ello es la aparición en el debate de aspectos como los derechos humanos, la paz, la justicia, el desarrollo y la equidad.

\title{
Reflexiones finales
}

En función de este ejercicio interpretativo, sustentado en una rigurosa revisión documental, surgieron algunos elementos importantes los cuales se deben esgrimir, esto en pro de contribuir en el debate en cuanto a la extensión y su praxis, generándose reflexiones y algunas recomendaciones que podrían ser consideradas bien sea en programas, proyectos y actividades que comúnmente hacen vida en el marco de la extensión universitaria.

La extensión universitaria, ya no es solo una tercera función de naturaleza social, ya no es un apéndice, ni brazo articulado de la universidad para responder a la sociedad; la extensión tiene una naturaleza esencialmente formativa, y debe reconocerse como tal, pues desde su praxis se aprende, se educa, se forma, se construye. Dando la posibilidad de una formación contextualizada y sensibilizada desde lo axiológico; la naturaleza de la extensión no solo debería ser un espacio de aplicación de aportes de la docencia y la investigación, sino que estas últimas deberían echar mano de aportes emergentes de la extensión, es decir, de la actividad extensionista pueden generarse conocimientos y avances en cuanto a la producción intelectual; naturalmente que ello demanda reconocerla como un espacio de integración y comunicación dinámica entre la universidad y la sociedad, donde la praxis extensionista: proyectos, programas y actividades sean una especie de tejido conjuntivo entre la vida intramuros y el contexto. 
A propósito de ello, durante todo el texto quedó claro que la extensión no ha de ser un componente de la vida académica inconexo con la docencia y la investigación, al contrario debe ser un asidero vital para el conocimiento científico, para la reflexión en cuanto a la gestión universitaria, así como también una caja de resonancia que estime la pertinencia social de la universidad y su compromiso con los cambios que hoy se demandan; la extensión universitaria entonces ha de tener una naturaleza recursiva, pues no solo aportará hacia las comunidades por medio de la aplicación de conocimiento y avances científicos, sino también desde la extensión se estima cuán pertinente y funcional es una universidad para su sociedad.

Sin embargo, la pertinencia de la extensión universitaria no solo radica en lo anterior, sino en la perspectiva que sustenta su praxis. De no haber consonancia entre los problemas y las medidas para afrontarlas, los resultados no serán favorables. De tal forma, que apostamos por una postura compleja, expresada en este ejercicio es un enfoque Bio-Eco-Ético-Social, un enfoque que asume al ser humano como un sujeto holístico, entramado en un contexto social, ambiental y planetario, entendiéndolo como un ser biológico, planetario, con carga axiológica e ineludiblemente social, imposibilitado de ser abordado en dimensiones particulares, pues la realidad no es como tal, no se puede entender una dimensión aislada de otras. Estas ideas sin duda deben ser consideradas como sustento en programas, proyectos, y actividades vinculadas con la extensión apostando a ser letra viva y aplicada.

Este último pensamiento es de vital importancia, pues hoy día en el marco de un contexto global, donde es avasallante la generación de conocimiento y su divulgación, cobra valía cuestionar ¿Qué tan útil es la producción intelectual para las sociedades?, ¿son cónsonos los conocimientos con lo que se vive en la actualidad?, diversos autores citados anteriormente, como Morín, Cabra, Leff y Schmidt, entre otros, comentan que la naturaleza de la realidad contemporánea es compleja, reticular, indeterminada, discontinua, interconectada, entonces sin duda las respuestas que la universidad debe considerar son de naturaleza compleja. Esto para la extensión universitaria es un territorio fértil para accionar; es allí donde la producción intelectual de la universidad tendrá mayor pertinencia y funcionalidad; planteamientos como estos son sin duda un llamado de atención para la universidad latinoamericana, en especial la venezolana, pues mucho se produce en trabajos de grado, tesis doctorales, trabajos de ascenso, entre otros documentos que se olvidan en bibliotecas y archivos, desfasados en tiempo y espacio, mientras hay un contexto el cual pide a gritos ser atendido.

No obstante, esta postura es poco funcional si no se entiende a la extensión como un espacio para el diálogo, un diálogo donde se respeta el pensar, el conocer y el sentir del otro; entendiéndose como un proceso sustentando desde la otredad; apuntando hacia la intersubjetividad, hacia el reconocimiento que tiene el otro como partícipe de las soluciones; este hecho garantiza el beneficio no solo de las comunidades atendidas, sino que también la universidad se fortalezca en cuanto a la adquisición de conocimientos, experiencias, alianzas estratégicas y reconocimiento institucional, buscando irrumpir esa visión tradicional donde la universidad solamente aporta sus conocimientos técnicos y científicos, sin generar un beneficio sustancial a la colectividad; vale acotar que al considerar a la extensión como un espacio dialógico resulta ineludible conjugar a lo científico y técnico con lo local, pues en las comunidades hay artesanos, cultores, artistas, innovadores, trabajadores sociales, entre otros personajes quienes debido a su praxis, ostentan conocimientos y saberes los cuales demandan ser reconocidos y valorados, dicha postura adiciona una carga axiológica importante a la extensión universitaria.

Por último, este modesto aporte, planteado en elementos teóricos para contribuir al debate y recomendar algunos aspectos que consideramos pertinentes. Primero, que la extensión universitaria y sus políticas no pueden ser estáticas, deben estar sujetas al contexto, al modus vivendi de las sociedades, a la naturaleza de las problemáticas abordadas y al contexto social, geográfico, económico y cultural, en muchos casos, se demanda de una universidad el salir de su zona de confort y entender que desde la extensión se pueden alcanzar múltiples propósitos en pro de la colectividad y la universidad. Segundo, se recomienda dejar a un lado la postura elitista de la universidad frente a las comunidades, pues ello imposibilita un diálogo de otredad; hay 
que reconocer a las personas que viven en las comunidades e incorporarlas a la dinámica extensionista, esto a la postre será ganancia para todos. Finalmente, se recomienda permear a la extensión universitaria y su praxis de un debate en planos epistemológicos y filósofos que inviten a repensarla y reflexionarla, no basta con hacer extensión de manera somera, es importante formular una extensión afín con las emergentes corrientes de pensamiento.

\section{ReFERENCIAS}

Arocena, R. (2011). Propuestas para el despegue de la reforma universitaria. Montevideo: Universidad de la República. Capra, F. (1992). El punto crucial. Ciencia, sociedad y cultura naciente. Buenos Aires: Editorial y Estaciones Capra, F. (1996). La trama de la vida. Una nueva perspectiva de los sistemas vivos. Barcelona: Editorial Anagrama

Del Huerto, E. (2007). La extensión universitaria como vía para fortalecer los vínculos Universidad-Sociedad desde la promoción de salud. Revista Cubana de Salud Pública.33(2), 3-12. Recuperado de https://goo.gl/Ty4UkT

Del Huerto, E. (2012). La extensión universitaria desde una perspectiva estratégica en la gestión integral de la universidad médica contemporánea. Educación Médica Superior, 26(4), 531-540. Recuperado de https://goo.gl/ $\mathrm{V} 2 \mathrm{YbsU}$

García, C. (2008). El compromiso social de las universidades. Memoria de Conferencia central en el IX Congreso Iberoamericano de Extensión Universitaria. Bogotá, Colombia. Cuadernos del Cendes, 67, 129-134.

Leff, E. (1998). Saber ambiental: Sustentabilidad, racionalidad, complejidad, poder. México: Siglo XXI editores

León, J. (2009). El ambiente: Paradigma del nuevo milenio. Caracas: Editorial ALFA

Machado, F. y García, C. (2014). Caracterización del entorno social comunitario como extensión universitaria en ciencias médicas. Revista de Educación Médica del Centro EDUMECENTRO, 6(2), 279-287. Recuperado de https://goo.gl/So4fLA

Martí, J. y Martí, M. (2013). Una década de responsabilidad social universitaria en Iberoamérica. Revista Española del Tercer Sector, (25), 145-161.

Martínez, C., Mavárez, R., Rojas, L. y Carvallo, B. (2008). La responsabilidad social universitaria como estrategia de vinculación con su entorno social. Revista Frónesis, 15(3), 81-103. Recuperado de https://goo.gl/uMGkgG

Morales, M., Mira, G. y Arias, M. (2010). Enfoques y retos de la función de extensión universitaria como mecanismo de integración: Universidad, Empresa, Estado. Memoria II Congreso Internacional de Gestión Tecnológica e Innovación. Bogotá, D. C., Colombia.

Morín, E. (1994). Introducción al pensamiento complejo. Madrid: Gedisa Editores

Morín, E. (1999). La cabeza bien puesta - Repensando la reforma reformar elpensamiento. Buenos Aires: Nueva Visión

Morín, E. (2000). Los siete saberes necesarios para la educación del futuro. UNESCO: Santillana

Naval, C., García, R., Puig, J. y Santos, M. (2011). La formación ético-cívica y el compromiso social de los estudiantes universitarios. Encounters on Education, 12, 77-91. Recuperado de https://goo.gl/vkz2yw

Ortiz, M. y Morales, M. (2011). La Extensión universitaria en América Latina: Concepciones y Tendencias. Revista Educación y Educadores. 2-14. Recuperado de https://goo.gl/6czP3w

Pérez, C., Silvia, N., Sainz, T. y Caridad, Z. (2014). La extensión universitaria como vía para fortalecer el trabajo educativo en la UCM de Pinar del Río. Revista de Ciencias Médicas de Pinar del Río, 18(5), 852-862.

Petz, I. (2015). Extensión universitaria: tendencias actuales y desafíos pendientes. Redes de Extensión. (1), 1-5

Sánchez, M. (2010). La Extensión Universitaria en Venezuela. Revista Educere, 8- 24

Sauve, L. (2004). Una cartografia de corrientes en Educación Ambiental. Cátedra de investigación de Canadá en educación ambiental. Montreal: Université du Québec

Schmidt, L. (2011). El Hombre como Ser-Ecosocial. Revista de Bioética Latinoamericana, 8(1), 18-35.

Tommasino, H. (2016). Modelos de extensión universitaria en las universidades latinoamericanas en el siglo XXI: tendencias y controversias. Universidades, (67), 7-24. Recuperado de https://goo.gl/raLxhh 
Francisco Pérez, et al. La extensión universitaria desde un enfoque bio-eco-ético-social. Diálogo ...

Torales, J. y Barrios I. (2017). Las necesidades de la sociedad, los derechos humanos y la extensión universitaria. En $L a$ extensión universitaria, esa posibilidad de crear una sociedad mejor (pp. 101-128). Paraguay: Universidad Nacional de Asunción.

Tünnermann, C. (1999). Realidad y perspectiva de la universidad en el contexto latinoamericano. Prospectiva, 1, 1-11

Tünnermann, C. (2000). El nuevo concepto de la extensión universitaria y difusión cultural y su relación con las políticas de desarrollo cultural en América Latina. Anuario de Estudios Centroamericanos, 4, 93-126

Vaccarezza, L. (2015). Apropiación social e hibridación de conocimientos en los procesos de extensión universitaria. Cuestiones de sociologia, (12). Recuperado de https://goo.gl/3pW2RV

Vásquez, I y Castillo, J. (2013). Extensión Universitaria: Un aporte para el desarrollo. Memoria del Foro Bienal Iberoamericano de Estudios del Desarrollo, 2013. Santiago de Chile.

\section{BY-NC-ND}

